\title{
Landslide Susceptibility Mapping Using Analytical Hierarchy Process, Statistical Index, Index of Enthropy, and Logistic Regression Approaches in the Tinalah Watershed, Yogyakarta.
}

\author{
Tee Xiong, I Gde Budi Indrawan;, and Doni Prakasa Eka Putra \\ Department of Geological Engineering, Faculty of Engineering, Gadjah Mada University, Yogyakarta, Indonesia
}

\begin{abstract}
A number of approaches have been used inlandslide susceptibility mapping and there seems to be no agreement on which approach provides best prediction of landslide susceptibility. This study was conducted to develop landslide susceptibility maps of the Tinalah watershed at a 1:25000 scale using analytical hierarchy process (AHP), statistical index (SI), index of entropy (IOE) and logistic regression (LR) approaches and to compare performance of those approaches in predicting landslide susceptibility. Out of 114 landslides identified during site investigation, 86 landslides were selected for landslide susceptibility analyses, while the remaining 28 landslides were used to verify the results. Factors controlling landslides considered in the landslide susceptibility mapping were slope inclination, lithology, distance to fault, land use, distance to river, and rainfall. Analyses of Receiver Operating Characteristics (ROC) curves showed that the AUC values of the landslide susceptibility maps derived using AHP, SI, IOE and LR approaches were $0.784,0.688,0.827$ and 0.834 , respectively. The LR approach was concluded to perform the best in predicting landslide susceptibility in the study area.
\end{abstract}

Keywords: Analytical hierarchy process · Index of entropy · Landslide susceptibility · Logistic regression - Statistical index.

\section{INTRODUCTION}

Landslide susceptibility maps provide information on landslide prone areas and are essentially determinedbased on identification of areas that have undergone past landslidesand areas having similar or identical physical characteristics. Glad and Crozier (2005) provides a review of approaches that have been used to produce landslide susceptibility maps. The approaches canbe classified into qualitative and quantitative approaches. Qualitative approaches are essentially based on expert knowledge and experience. The approaches are subjective and, therefore, difficult to be applied to different areas. Prabin (2010) mentioned that AHP developed by Saaty (1980) is a very popular qualita-

${ }^{*}$ Corresponding author: I G.B. INDRAWAN, Department of Geological Engineering, Gadjah Mada University. Jl. Grafika 2 Yogyakarta, Indonesia. E-mail: igbindrawan@ugm.ac.id tive or semi-qualitative method which converts subjective assessments of relative importance to a set of overall scores or weights. Meanwhile, quantitative approaches involve mapping of statistically large number of parameters consider to influence the landslide to derive a predictive relationship between the terrain conditions and the occurrence of landslides. The approaches are based on statistical approaches (Lee and Jones, 2004). Statistical approaches have been adopted for landslide susceptibility zonation to minimize uncertainties in weight assignment procedures associated with qualitative approaches due to subjectivity. Statistical analyses are popular because they provide a more quantitative analysis of slope instability, have ability to examine the various effects of each factor on an individual basis and decide on the result of mapping in an interactive manner (Aleotti and Chowdhury, 1999). The SI (e.g., Pourghasemi et al., 2013), IOE (e.g., Devkota et 
al., 2013; Pourghasemi et al., 2013; Wang et al., 2016), and LR (Devkota et al., 2013) are a fewexamples of quantitative approaches employedin landslide susceptibility mapping.

The AHPis a multiple criteria decisionmaking technique that allows subjective as well as objective factors to be considered in the decision-making process (Yalcin, 2008). In a comparative study, Yalcin (2008) found that the AHP approach gave a more realistic picture of the actual distribution of landslide susceptibility, than the SI approach. Mancini et al. (2010), Pradhan (2010), Youssef et al. (2015), and Kavzoglu (2015) found that the LR approachshowsa landslide susceptibility prediction better than the SI approach. Shahabi et al. (2013), Devkota et al. (2013), and Pourghasemi et al. (2013) indicated that the LR approach had a high prediction performance of landslide susceptibility zone, as compared to the AHP, IOE, and SI approaches. Akbari et al. (2014) was also mentioned that the LR approachwas reliable to predict the landslide susceptibility. Furthermore, Wang et al. (2016) mentioned that the SI and IOE approachesgave similar resultsin landslide susceptibility analyses. Those previous studies indicate that there seems to be no agreement on which approach provides the best prediction of landslide susceptibility.

Hilly morphology and poor engineering geological conditions most likely contributed to the susceptibility of the Tinalah Watershed to landslides. This paper presents results of landslide susceptibility mapping in the watershed using the AHP, SI, IOE and LR approaches. The methodology for the landslide susceptibility analysis using those approached is described. Comparison of the landslide susceptibility analysis results obtained from these approaches and the accuracy of those approaches in predicting landslide susceptibility is highlighted.

\section{THEORY}

In the landslide susceptibility analysis using the AHP approach, each class of the parameters is assigned a score, where the highest score indicates the most susceptible parameter to cause a landslide. After scoring each class of the parameters, the weight of each parameter is assigned using a pairwise comparison technique based on the relative importance of the parameter. Consistence of the weights assigned to the parameters is verified using the consistency ratio $(C R)$, which is based on consistency index $(C I)$, as described in the following Equations (1) and (2) (Saaty, 1980):

$$
\begin{aligned}
& C I=\frac{\lambda_{\max }^{-n}}{n-1} \\
& C R=\frac{C I}{R I}
\end{aligned}
$$

where $\lambda_{\max }=$ the maximum of eigenvalue; $n=$ the number of rows and columns; and $R I=$ random consistency index. The assigned weights for the parameters are considered to be acceptable once the calculated $C R$ was less than 1. Saaty (1980) suggested that a consistency ratio $(C R)$ close to 0 indicates that the probability of the assigned weights to the parameters generated randomly is high. Landslide susceptibility index (LSI) of the AHP approach canthen be calculated using Equation (3) (Voogd, 1983), as follows:

$$
L S I=\sum_{i=1}^{n} R_{i} \times W_{i}
$$

where $R_{i}=$ the rating class of parameter $i$; $W_{i}=$ the weight of parameter $i ; n=$ number of parameter. The LSI represents the relative occurrence of landslide. The LSI value obtained from the AHP approach, as well as the other approaches, can be divided into several levels of landslide susceptibilities using a classification system of natural breaks.

In the landslide susceptibility analysis using the SI approach, calculation of landslide density for each class ofthe parametersis performed to compute the weight of each class of the parameters. To calculate the density of each class, each of the parametric maps and the landslide inventory map is overlaid using combination of spatial analysis tools in GIS to produce new layers, where each layer containsthe pixel number of landslides in each class. One pixel may represent an area of landslide. The pixel numbers of landslides are then changed into percentage of each class. The weight of each class $\left(W_{i j}\right)$ is defined as the natural logarithm density in the categorical unit divides by the landslide density in the entire map and is calculated using Equation 
(4), as follows (Van Westen, 1997; Pourghasemi et al., 2013):

$$
W_{i j}=\ln \left[\frac{E_{i j}}{E}\right]=\ln \left[\frac{L_{i j} / L_{T}}{P_{i j} / P_{T}}\right]
$$

where $W_{i j}=$ the weight given to a certain class $i$ of landslide causative factor $j ; E_{i j}=$ the landslide density within class $i$ of landslide causative factors $j ; E=$ the total landslide density within the entire map; $L_{i j}=$ the number of landslide in certain class $i$ of landslide causative factor $j ; P_{i j}=$ the number of pixel in a certain class $i$ of landslide causative factor $j ; L T=$ the total number of landslide in the entire map; PT $=$ the total pixels of the entire map. The calculation of class weight is only performed for the class with landslide occurrence. For any class without landslide occurrence, the weight is assigned to be zero. The landslide susceptibility index (LSI) can thenbe computed using Equation (5) as follows (Van Westen, 1997; Pourghasemi et al., 2013):

$$
L S I=\sum_{i j}^{n} W_{i j}
$$

where $W_{i j}=$ the weight of class $i$ in parameter $j ; n=$ the total number of landslide causative factors.

In the landslide susceptibility analysis using the IOE approach, the following Equations (6) to (11) can be used to calculate the weight of each parameter $\left(W_{j}\right)$ (Devkota et al., 2013; Wang et al., 2015):

$$
\begin{gathered}
P_{i j}=\frac{b}{a} \\
\left(P_{i j}\right)=\frac{P_{i j}}{\sum_{j=1}^{S_{j}} P_{i j}} \\
H_{j}=-\sum_{j=1}^{S_{j}}\left(P_{i j}\right) \log _{2}\left(P_{i j}\right) \\
H_{j \max }=\log _{2} S_{j} \\
I_{j}=\frac{H_{j \max }-H_{j}}{H_{j \max }} \\
W_{j}=I_{j} \times P_{j}
\end{gathered}
$$

where $P_{i j}=$ the density of class $i$ in parameter $i ; a=$ the domain percentage, which is represented by the number pixel of class divided by the total pixels of the entire map; $b=$ landslide percentage, which is represented by the number of landslide in class divided by the total landslides; $\left(P_{i j}\right)=$ the probability of landslide densityof class $i$ in parameter $j ; S_{j}=$ number of classes; $H_{j}$ and $H_{j \max }=$ entropy values; $I j=$ the information coefficient of parameter $j$, where the value of $I$ ranges from 0 to 1 . The landslide susceptibility index, which expresses the sum of all parameter classes and is ranked according to the calculated landslide density for each class, can be determined using Equation (12):

$$
L S I=\sum_{i=1}^{n} \frac{z}{m_{i}} \times C \times W_{j}
$$

where $i=$ the number of parametric map (1, $2, \ldots n) ; z=$ the number of classess within parametric map with the greatest number of classes; $m_{i}=$ the number of classes within parametric map; $C=$ the value of the class after secondary classification.

The LR approach allows analysis of a multivariate regression relation between a dependent variable (the presence or absence of landslides) and a number of independent variables (i.e., slope inclination, distance to river, lithology, distance to fault, and land use). The approach generates the model statistics and coefficients of a formula which is useful to predict a logit transformation of the probability that the dependent variable is 1 (probability of occurrence of a landslide event) (Ayalew and Yamagishi, 2005). In the landslide susceptibility analysis using the LR approach, the probability of landslide occurrence can be calculated using Equations (13) and (14) (Ayalew and Yamagishi, 2005; Lee and Pradhan, 2007; Pradhan, 2010; Devkota et al., 2013):

$$
\begin{gathered}
P=\frac{1}{\left(1+e^{-z}\right)} \\
z=\beta_{0}+\beta_{1} x_{1}+\beta_{2} x_{2}+\cdots+\beta_{n} x_{n}
\end{gathered}
$$

where $P=$ the probability of landslide occurrence, which varies from 0 to $1 ; z=$ a linear combination of independent variables; $\beta_{0}=$ the 
intercept or statistically constant coefficient, $\beta_{1}$, $\beta_{2}, \cdots, \beta_{n}=$ the coefficients of logistic regression model, $x_{1}, x_{2}, \ldots, x_{n}=$ the independent variables, $n=$ the number of independent variables. Estimation ofthe logistic regression coefficient of each parameter can be performed using the backward elimination (backward likelihood ratio) approach. The standard errors of the estimations are set to be between 0.001 and 0.005 and $R^{2}$ being greater than 0.2 can be an accepted model as influential predictor variables (Van den Eekhaut et al., 2006).

\section{Study AREA}

The Tinalah Watershed is located in Yogyakarta Special Province (Indonesia) and covers an area of $64 \mathrm{~km}^{2}$ consisting of five sub-districtsin $\mathrm{Ku}$ lonProgo Regency, namely Borobudur, Samigaluh, Kalibawang, Girimulyo, Nanggulan, and Minggir (Figure 1). The slopesin the watershed varied from 0 to $69^{\circ}$ and the altitude ranged from 62.6 to $987.5 \mathrm{~m}$ above sea level. As larger parts of the watershedwere hills and smaller parts were plains, the drainage or stream systems weretypicallyshort and had steep longitudinal morphometries which abruptly changed into gentler slopes. The Tinalah River was one of the major tributaries of The Progo River, which was the main river flowing from Central Java Province to southern part of Yogyakarta Special Province. A number of landslides occurred in the watershedmost likely due to the hilly morphology and poor engineering geological conditions (Figure 2).

\section{Methodology}

\subsection{Landslide susceptibility parameters}

Factors controlling landslides considered as input parameters in the landslide susceptibility analyses wereslope inclination, river, lithology, fault, land use, and rainfall. Field mappingwas conducted to verify spatial distributions of slope inclinations and rivers derived from a digital elevation model (DEM), lithologies and faults derived from regional geological map of Yogyakarta Sheet prepared by Rahardjo et al. (1995), and land uses derived fromTopographical Map of Indonesia, upon which parametricmaps of slope inclination, distance to river, lithology, distance to fault, and land use were developed, respectively. Rainfall inten- sity map was developed from annual rainfall data recorded from 2006 to 2015 in five rainfall stations located in the watershed and the surrounding area. In addition, landslide locations were recorded for development of a landslide inventory map.In total, 114 landslides were identified during the field investigation. Out of those total landslides, 86 landslides (75.4\%) were randomly selected for the landslide susceptibility analyses using the AHP, SI, IOE and LR approachesand called landslide training, while the remaining 28 landslides (24.6\%)were used to verify results of the landslide susceptibility analysesand called landslide verification. The landslides were digitized and rasterized in GIS with a grid size of $20 \times 20$ m.Other vector data layers (i.e., slope inclination, distance to river, lithology, distance to fault, and land use maps) were also rasterized with this size.

\subsection{Landslide susceptibility zonation}

The landslide susceptibility analyses required division of each parameter into a number ofsub parameters or classes. The slope was divided into seven classes, i.e., flat $\left(0-2^{\circ}\right)$, gently slope $\left(2-4^{\circ}\right)$, sloping $\left(4-8^{\circ}\right)$, moderately steep $\left(8-16^{\circ}\right)$, steep $\left(16-35^{\circ}\right)$, very steep $\left(35-55^{\circ}\right)$ and extremely steep $\left(>55^{\circ}\right)$, following a terrain classification proposed by Van Zuidam (1983). The lithology was divided into five classes as observed in the field mapping, namely sand-clay deposit, ash, breccia and tuff, sandstone and limestone, and andesitic breccia. The distance to riverwere divided into three classes, namely 0-50 m, 50-100 m, and more than $100 \mathrm{~m}$, which were essentially modification of the classification proposed by Varnes (1984). The distance to fault was divided into three classes, namely less than $500 \mathrm{~m}, 500-1000 \mathrm{~m}$, and more than $1000 \mathrm{~m}$ following the classification proposed by Varnes (1984). The rainfall intensity was classified into three classes, namely less than 1800 $\mathrm{mm} / \mathrm{yr}, 1800-2000 \mathrm{~mm} /$ year, and more than $2000 \mathrm{~mm}$ /year.

In the landslide susceptibility analysis using the AHP approach, each class of the parameters was assigned a scoreranging from 1 to 5 , where the highest score indicated the most susceptible parameter to cause a landslide. The CI and $C R$ values were calculated using Equations (1) and (2), respectively, while the LSI wascalculated based on Equation (3). The higher the LSI 


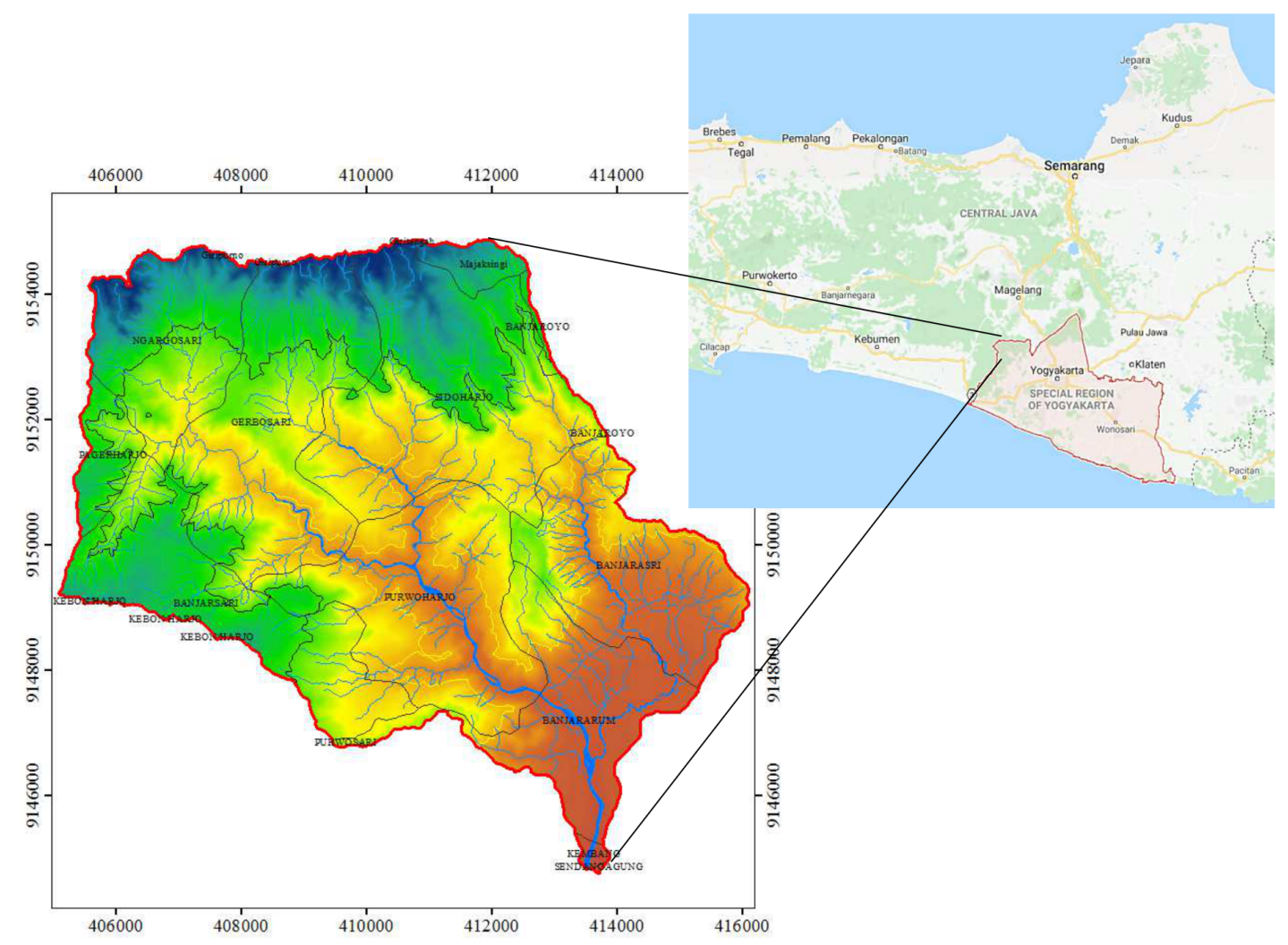

Figure 1: Study area.

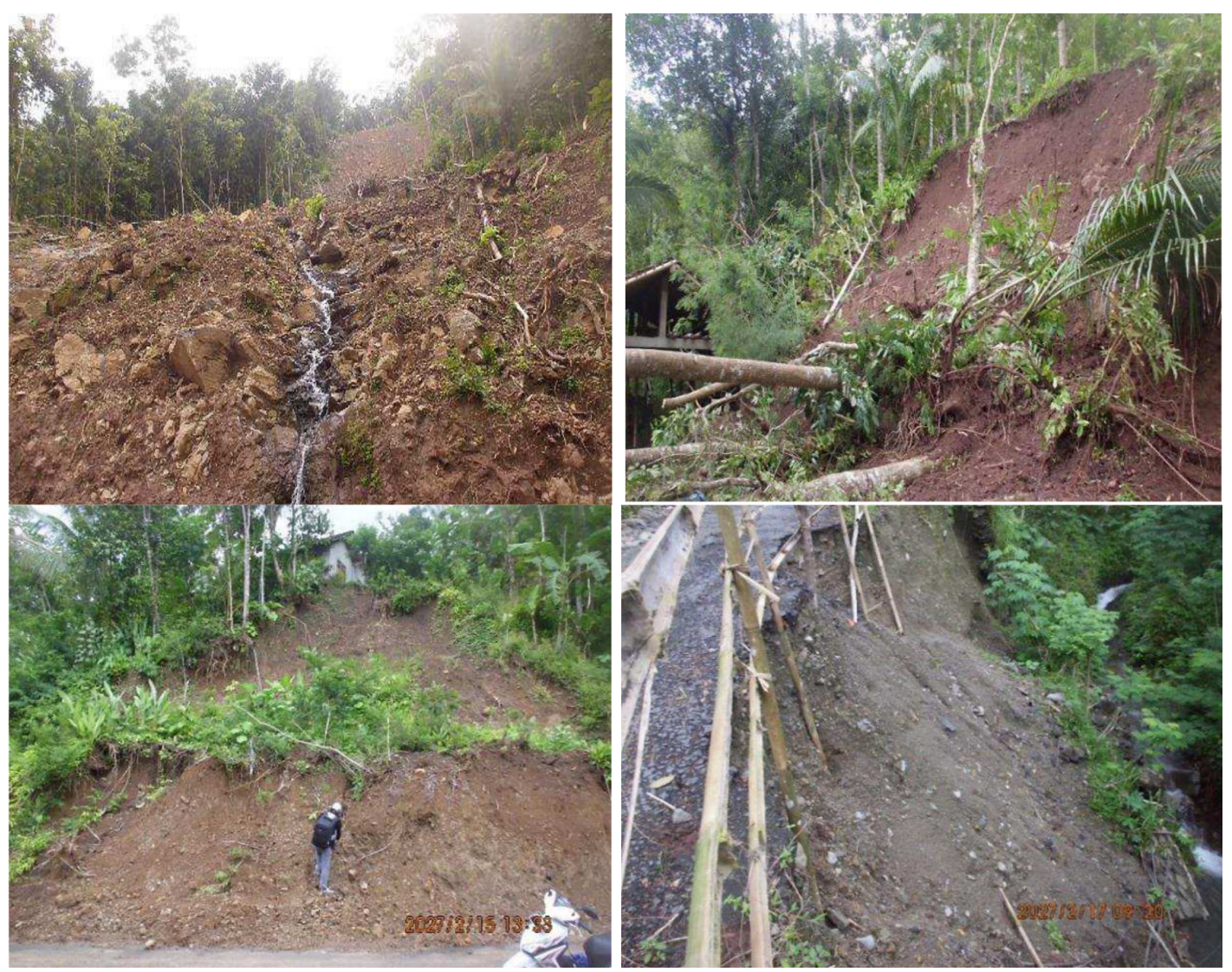

Figure 2: Typical landslides in the study area. 
was, the more susceptible the area to landslide would be. The LSI calculation showed that the LSI had a minimum value of 1 and a maximum value of 5 , with a mean value of 3.40 and a standard deviation of 0.75 . In the landslide susceptibility analysis using the AHP approach, the study area was divided into three different zones of the landside susceptibility: low susceptibility (i.e., LSI $<2.67$ ), moderate susceptibility (i.e., $2.67 \leq L S I \leq 3.60)$ and high susceptibility (i.e., $L S I>3.60$ ).

In the landslide susceptibility analysis using the SI approach, the weight of each class $\left(W_{i j}\right)$ was calculated using Equation (4), while the LSI was calculated based on Equation (5). The LSI calculation showed that the LSI values were in the range of -6.18 to 1.95 , with the mean value of -0.84 and standard deviation of 1.24 . The study area was then divided into three different zones of the landside susceptibility: low susceptibility (i.e., LSI <-2.37), moderate susceptibility (i.e., $-2.37 \leq L S I \leq-0.57$ ) and high susceptibility (i.e., $L S I>-0.57$ ).

In the landslide susceptibility analysis using the IOE approach, the weight of each parameter $\left(W_{j}\right)$ was computed using Equations (6) to (11). The LSI was determined using Equation (12). The calculation results showed that the LSI values were in the range of 0.36 to 1.32 , with the mean value of -0.96 and standard deviation of 0.17 . The study area was then divided into three different zones of the landside susceptibility: low susceptibility (i.e., $L S I<0.68$ ), moderate susceptibility (i.e., $0.68 \leq L S I \leq$ $0.96)$ and high susceptibility (i.e., $L S I>0.96$ ). In the landslide susceptibility analysis using the LR approach, the probability of landslide occurrence was calculated using Equations (13) and (14). All parameters and landslide data were converted into ascii (.txt) file format, upon whichall data were exported into SPSS software for estimation ofthe logistic regression coefficient of each parameter using the backward elimination (backward likelihood ratio) approach.

\subsection{Verification of landslide susceptibility maps}

In order to determine the accuracies of the AHP, SI, IOE and LR approaches in predicting the landslide susceptibility zones in the study area, the landslide susceptibility maps developed us- ing the AHP, SI, IOE and LR approaches were overlaid with the landslide verification data (i.e., 28 landslides), upon which analyses of Receiver Operating Characteristics (ROC) curves were performed using SPSS software. Previous researchers (e.g.,Lee and Pradhan, 2007; Pourghasemi et al., 2013; Devkota et al., 2013) had used the area under the curve (AUC) of the ROC curve to compare performance of different approaches in landslide susceptibility analyses. Following the classification proposed by Yesilnacar and Topal (2005), the landslide susceptibility approaches with the AUC values of $0.9-1,0.8-0.9,0.7-0.8,0.6-0.7$, and $0.5-0.6$ were considered to have excellent, very good, good, average, and poor prediction accuracy, respectively. Higher accuracy of the landslide susceptibility approaches in predicting occurrence of landslide was, therefore, inferred from the higher AUC value.

\section{Results AND Discussion}

\subsection{Landslide susceptibility parameters}

Slope morphology influences the stability of materials constituting the slope. Under gravity loading, the steeper the slope is, the lower the stability of theslope will be. Based on the elevation and slope inclination, the watershedin the study area could be divided into three slope morphologies, namelyupslope, midslope, and lower slope. The upper slope of the watershed had a slope inclination greater than $27^{\circ}$ and covered the areas from the north to the southwest of the watershed. The midslope of the watershed had aslope inclination ranging from 12 to $27^{\circ}$ and covered the areas in the middle of the watershed. Meanwhile, the lower slope of the watershed had aslope inclination less than $12 \mathrm{o}$ and covered the areas in the southeast of the watershed. Map of slope inclination in the study area used in the landslide susceptibility analysesis shown in Figure 3(a).

Erosion of river bank toe due to undercutting action of flowing water may induce landslide. In addition, stream water may increase saturation degree of slope materials, leadingto a reduction of shear strength of the materials and, subsequently, landslides. As anumber of landslides along the rivers in the study area were observed during the field investigation, distanceto the river was, therefore,also considered as one 

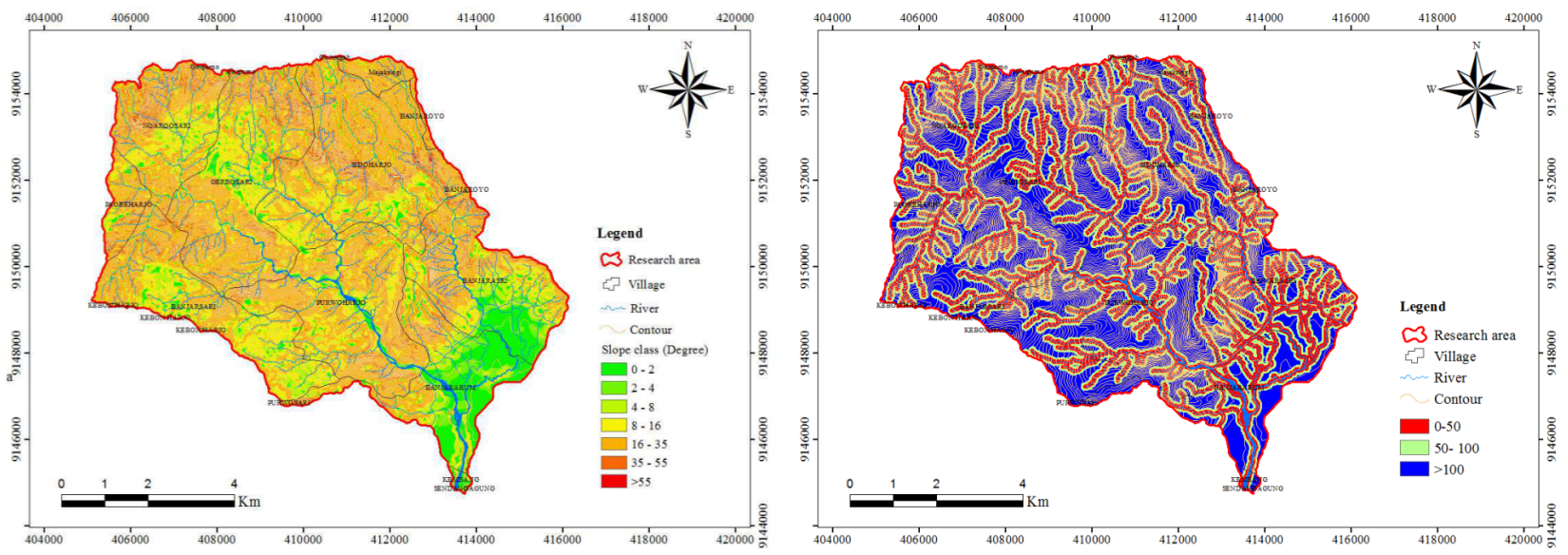

(a)

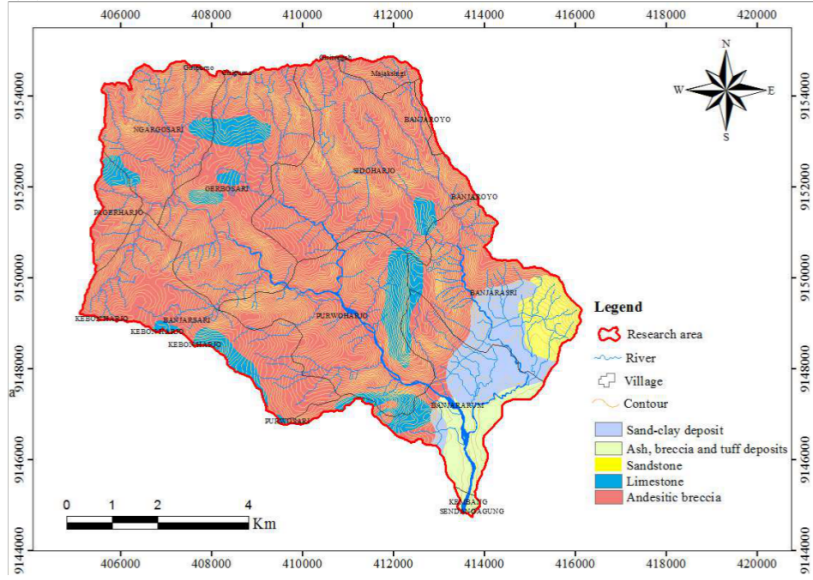

(c)

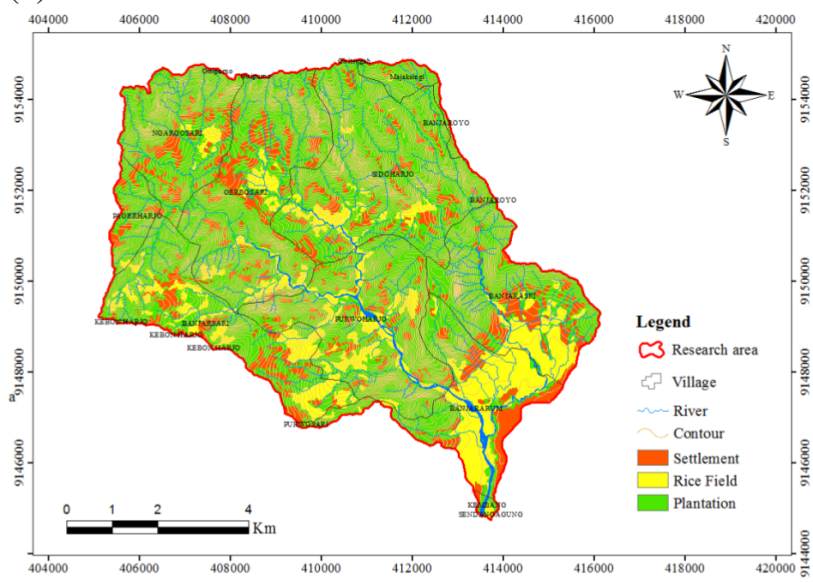

(e) (b)

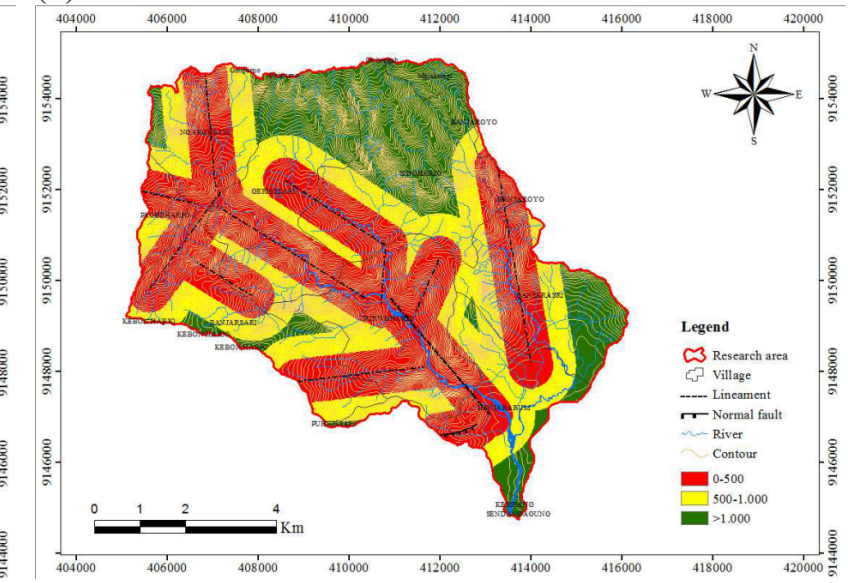

(d)

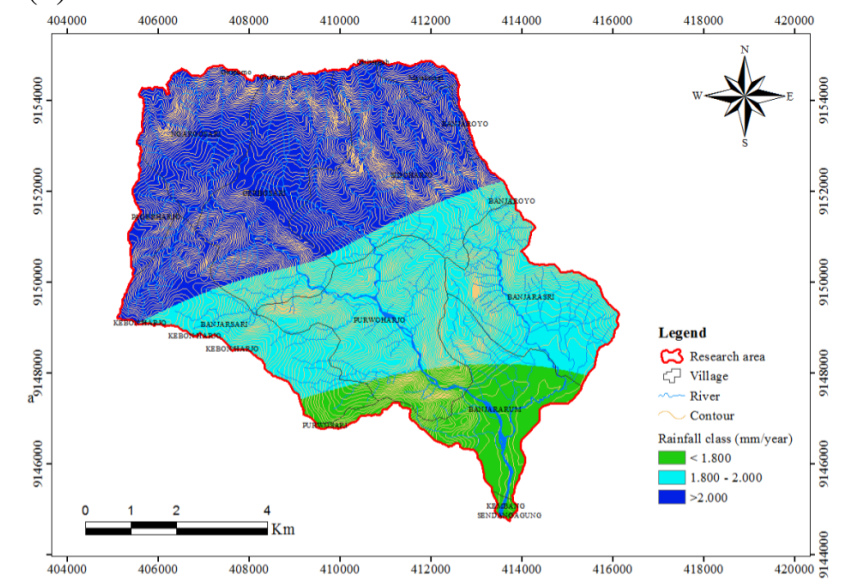

(f)

Figure 3: Maps of landslide susceptibility parameters: (a) slopeinclination;(b) distance from river map; (c) lithology; (d) distance from fault; (e) land use map; and(f) rainfall intensity. 
of landslide controlling parameters in the development of landslide susceptibility maps. Areas closer to the rivers were likely to be more susceptible to landslides. Mapof distance from river in the study area used in the landslide susceptibility analysesis shown in Figure 3(b).

Rock type and the weathering degree influence the susceptibility of slopes to landslides. Igneous and non-foliated metamorphic rocks tend to have higher strength as compared to volcanic, sedimentary, and foliated metamorphic rocks. Weathering reduces cohesive rock strength so that for the same rock type, the higher the weathering degree is, the more susceptible to landslide will be. Based on the field mapping, the rock types found in the area were andesite breccia, limestone, sandstone, ash, breccia and tuff deposits and sand-clay deposits (Figure 3(c)). In reference to the Regional Geological Map of Yogyakarta Sheet (Rahardjo et al., 1995), the andesitic breccia was a member of the Kebobutak Formation, the limestone was a member of the Jonggrangan Formation, the sandstone was a member of the Jonggrangan Formation, the ash, breccia and tuff were members of the Young Volcanic Deposit, while the sand-clay deposit was a member of the Colluvium Deposit. Under a tropical climate, most rocks in the study area were highly weathered. The andesitic breccia, ash, breccia, and tuff deposits, and sand-clay deposits tended to have lower strength than the sandstone and limestone. Most landslides were found in sloping areas consisting of thehighly weatheredandesite breccia.

Fault displacements tend to form weak zonesof fractured rock masses having a relatively low cohesive strength. In addition, the fractured rock massesalso tend to have a relatively high permeability for water infiltration, which promotes more intensive weathering process and, subsequently rock strength reduction. Therefore, the closer the area from the fault zone is, the higher the probability of landslides to occur will be. The zones of distance from fault in the study area used in the landslide susceptibility analyses are shown in Figure 3(d). In agreement to the structural data presented in Rahardjo et al. (1995), a normal fault trending northwest-southeast and cutting through the limestone of the Jonggrangan Formation and the andesite breccia of the Kebobutak Formationwas identified in the southern part of the watershed.In addition to the identified normal fault line, zones of distance from fault shown in the map also includedzones of distance from lineaments inferred from changes of topographic characteristics.

In the plantation areas, vegetation may reduce water infiltration into the slopes by intercepting rain water. Although housing and the infrastructure in the settlement areas may reduce rainwater infiltration, increase of loads induced by the housing and infrastructures may cause landslides. Irrigation of rice fields during planting seasons leads to soil saturation and water infiltration that may induce landslides. Land uses existing in the study area were plantation-forest, settlement, and rice field, as shown in Figure 3(e). Although landslides more likely occur in the rice field areas than in the plantation areas, landslideswere found mostly in the plantation and settlement areas because both land uses were located in sloping areas while rice fields were mostly developed in low lands.

Increase of pore water pressure due to rain water infiltration reduces soil and rock strength that may lead to landslides. Areas with more rainfall will likely be more susceptible to landslide. Map of rainfall intensity in the study area is shown in Figure 3(f). The northern part of the study area had the highest rainfall intensity, while the southern part had the lowest. The peak amount of rainfall typically occurred in January, February, March, November and December, while the lowest amount of rainfall occurred in August.

\subsection{Landslide susceptibility zone}

Result of the pairwise comparison based on the relative importance of the parameter in the landslide susceptibility analysis using the AHP approach is shown in Table 1. The score of each class and the weight of each parameter assigned in the landslide susceptibility analysis using the AHP approach are shown in Table 2. The calculated $C R$ was 0.04 or close to 0 . The landslide susceptibility map developed using the AHP approach is shown in Figure 4 and landslide density in each of the landslide susceptibility zones is shown in Table 3. It is shownthat the study area dominantly consisted of high land- 
slide susceptibility zone. Although landslides mostly occurred in high landslide susceptibility zone, the highest density of landslides was located in the moderate landslide susceptibility zone.

Calculation results of landslide density and weight for each class of the parameters in the landslide susceptibility analysis using the SI approach are shown in Table 4 . A positive weight value of a class indicates a relationship exists between the class and landslide occurrence. The stronger the relationship is, the higher the class weight value will be. On the contrary, a negative weight value of a classindicates that the class is not related to the landslide occurrence. The positive, highest value of weight $\left(W_{i j}\right)$ for the classes of slope inclination of $16-35^{\circ}$, lithology of andesitic breccia, distance from fault of $0-500 \mathrm{~m}$, land use of settlement, distance from river of more than $100 \mathrm{~m}$, and annual rainfall of $1800-2000 \mathrm{~mm} / \mathrm{yr}$ in each of the parameters indicates that those classes of parameters had the most dominant influence on the occurrence of landslides in the study area. The landslide susceptibility map developed using the SI approach is shown in Figure 5 and landslide density in each of the landslide susceptibility zones is shown in Table 3. It is shown that the study area consists dominantly of high landslide susceptibility zone having the highest percentage and density of landslides.

The calculated weight of each parameter in the landslide susceptibility analysis using the IOE approach is shown in Table 5. The highest value of density probability $\left(P_{i j}\right)$ for classes of slope inclination of $16-35^{\circ}$, lithology of andesitic breccia, distance from fault of 0-500m, land use of settlement, distance from riverof more than $100 \mathrm{~m}$, and annual rainfall of $1800-2000 \mathrm{~mm} /$ yrin each of the parameters indicates that those classes of parameters had the most dominant influence on the occurrence of landslides in the study area. The landslide susceptibility map developed using the IOE approach is shown in Figure 6 and landslide density in each of the landslide susceptibility zones is shown in Table 3. It is shown that the study area consists dominantly of high landslide susceptibility zone having the highest percentage and density of landslides.

The logistic regression coefficient of each pa- rameter in the landslide susceptibility analysis using the LR approach is shown in Table 6. Coefficients of logistic regression indicate contribution of the parameters (i.e., factors controlling landslide) to the landslide occurrence. It is shown that slope inclination, lithology, land use, and distance from river hadan important rolein occurrence of landslidesin the study area. The landslide susceptibility map developed using the LR approach is shown in Figure 7 and landslide density in each of the landslide susceptibility zones is shown in Table 3 . It is shown that the study area consists dominantly of high landslide susceptibility zone having the highest percentage and density of landslides.

\subsection{Verification of landslide susceptibility maps}

The ROC curves of landslide susceptibility maps derived using the AHP, SI, IOE and LR approaches are shown in Figure 8. The AUC values of the landslide susceptibility maps derived using $\mathrm{AHP}, \mathrm{SI}, \mathrm{IOE}$ and LR approaches were $0.784,0.688,0.827$ and 0.834 , respectively. The AHP approach had a good prediction accuracy $(78.4 \%)$, the SI approach had an average prediction accuracy $(68.8 \%)$, while the IOE and LR had very good prediction accuracies $(82.7 \%$ and $83.4 \%)$. The higher prediction accuracy of the AHP approach than the SI approach obtained in this study was similar to that obtained by Yalcin (2008). Results obtained in this study were also similar to those obtained by Pourghasemi et al. (2013), where the LR approach performed the best in predicting landslide susceptibility, followed by the AHP approach, and lastly the SI approach.

\section{CONCLUSION}

In this study, landslide susceptibility maps were developed using analytical hierarchy process (AHP), statistical index (SI), index of entropy (IOE) and logistic regression (LR) approaches.Five factors controlling landslides, namely slope inclination, river, lithology, fault, land use, and rainfall, were considered as input parameters in the landslide susceptibility analyses. Analyses of Receiver Operating Characteristics (ROC) curves showed that the AUC values of the landslide susceptibility maps derived using AHP, SI, IOE and LR approaches were $0.784,0.688,0.827$ and 0.834 , respectively. 
Table 1: Pairwise comparison matrix in landslide susceptibility analysis using the AHP approach.

\begin{tabular}{lcccccc}
\hline Parameter & $\begin{array}{c}\text { Slope } \\
\text { inclination }\end{array}$ & Lithology & $\begin{array}{c}\text { Distance to } \\
\text { fault }\end{array}$ & Land use & $\begin{array}{c}\text { Distance to } \\
\text { river }\end{array}$ & Rainfall \\
\hline Slope inclination & 1 & 2 & 5 & 1 & 3 & 3 \\
Lithology & $1 / 2$ & 1 & 3 & $1 / 2$ & 3 & 2 \\
Distance to fault & $1 / 5$ & $1 / 3$ & 1 & $1 / 2$ & $1 / 3$ & 1 \\
Land use & 1 & 2 & 2 & 1 & 2 & 3 \\
Distance to river & $1 / 3$ & $1 / 3$ & 3 & $1 / 2$ & 1 & 2 \\
Rainfall & $1 / 3$ & $1 / 2$ & 1 & $1 / 3$ & $1 / 5$ & 1 \\
\hline
\end{tabular}

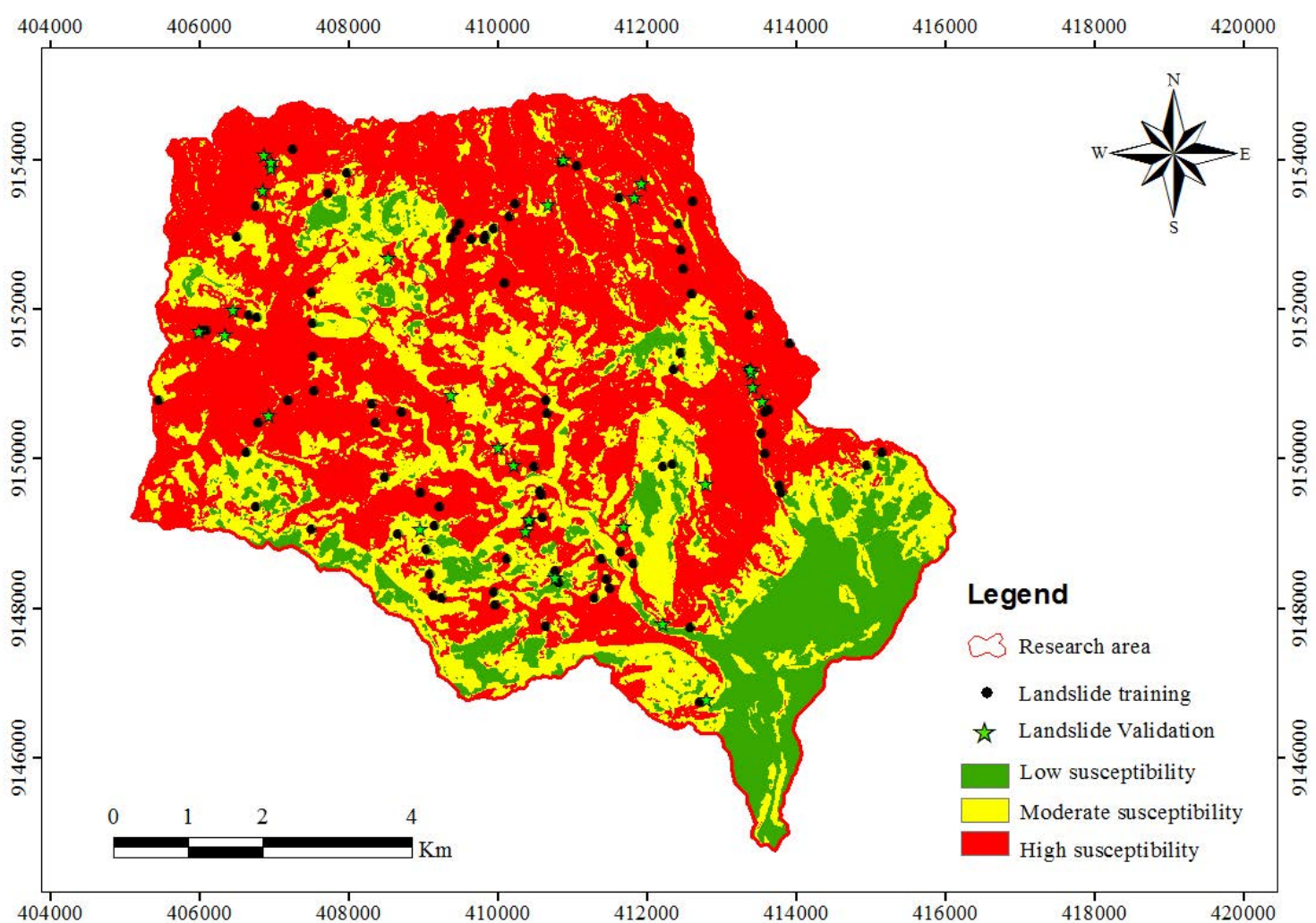

Figure 4: Landslide susceptibility mapdeveloped usingthe AHP approach. 


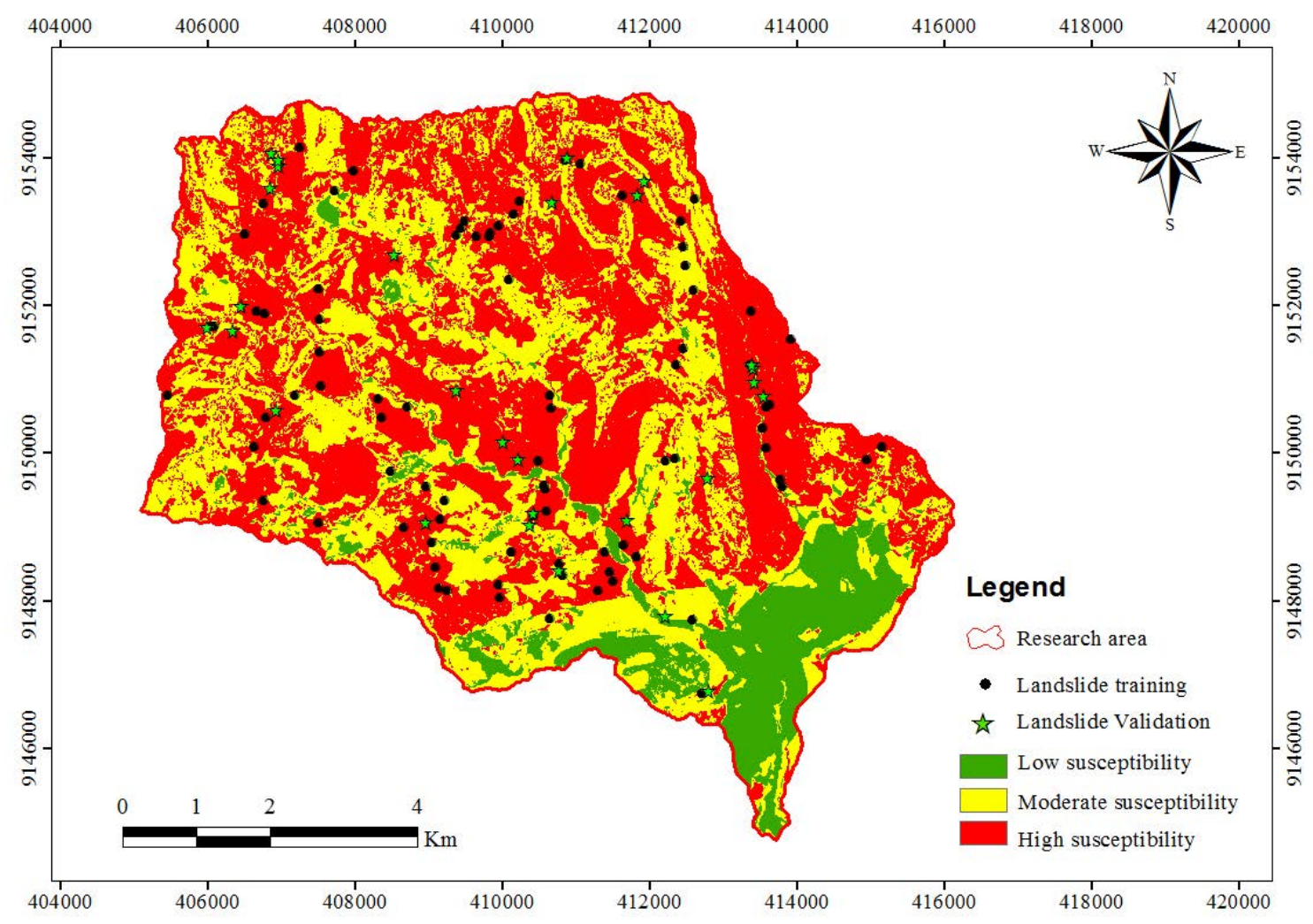

Figure 5: Landslide susceptibility mapdeveloped usingthe SI approach.

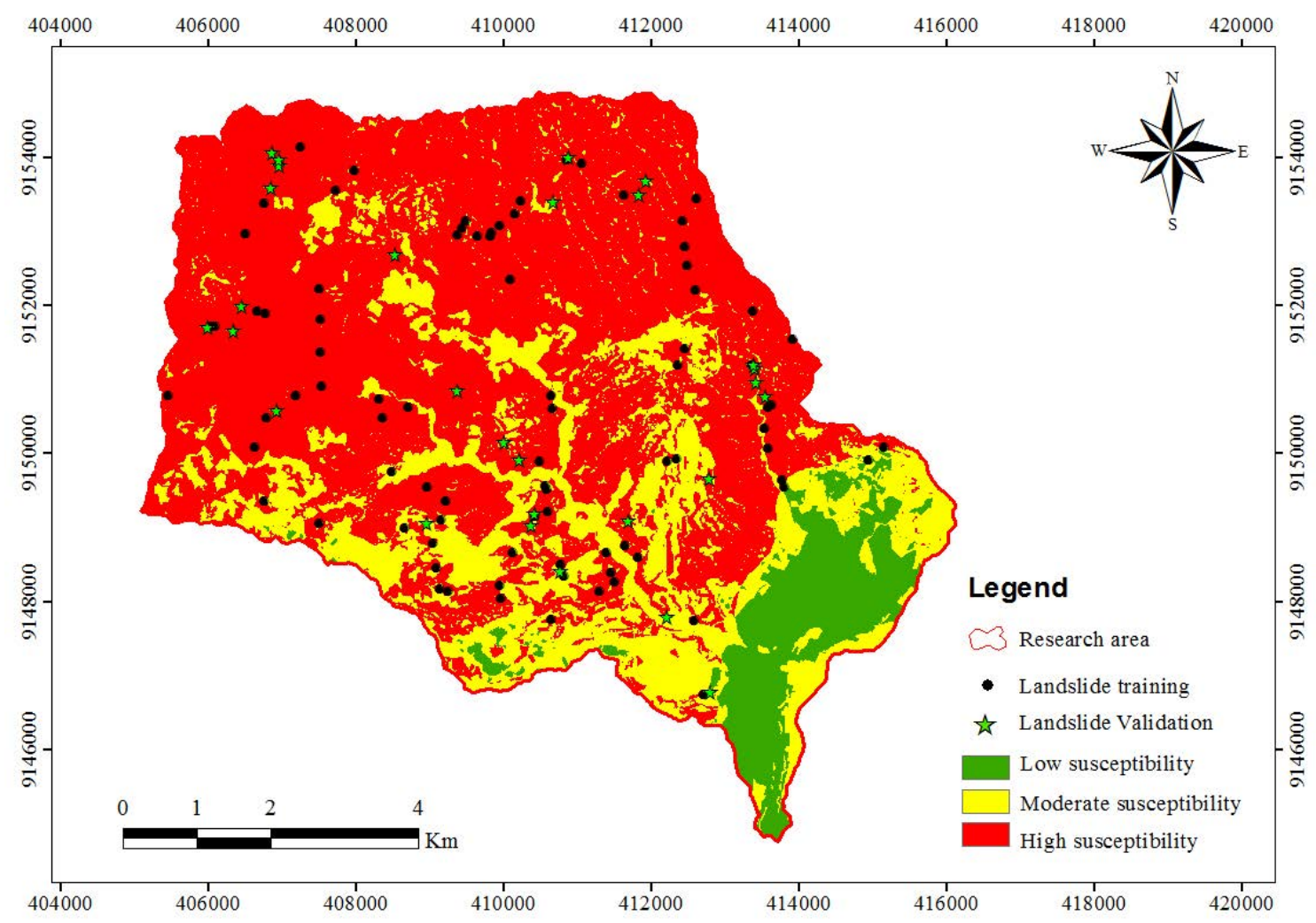

Figure 6: Landslide susceptibility mapdeveloped usingthe IOE approach. 


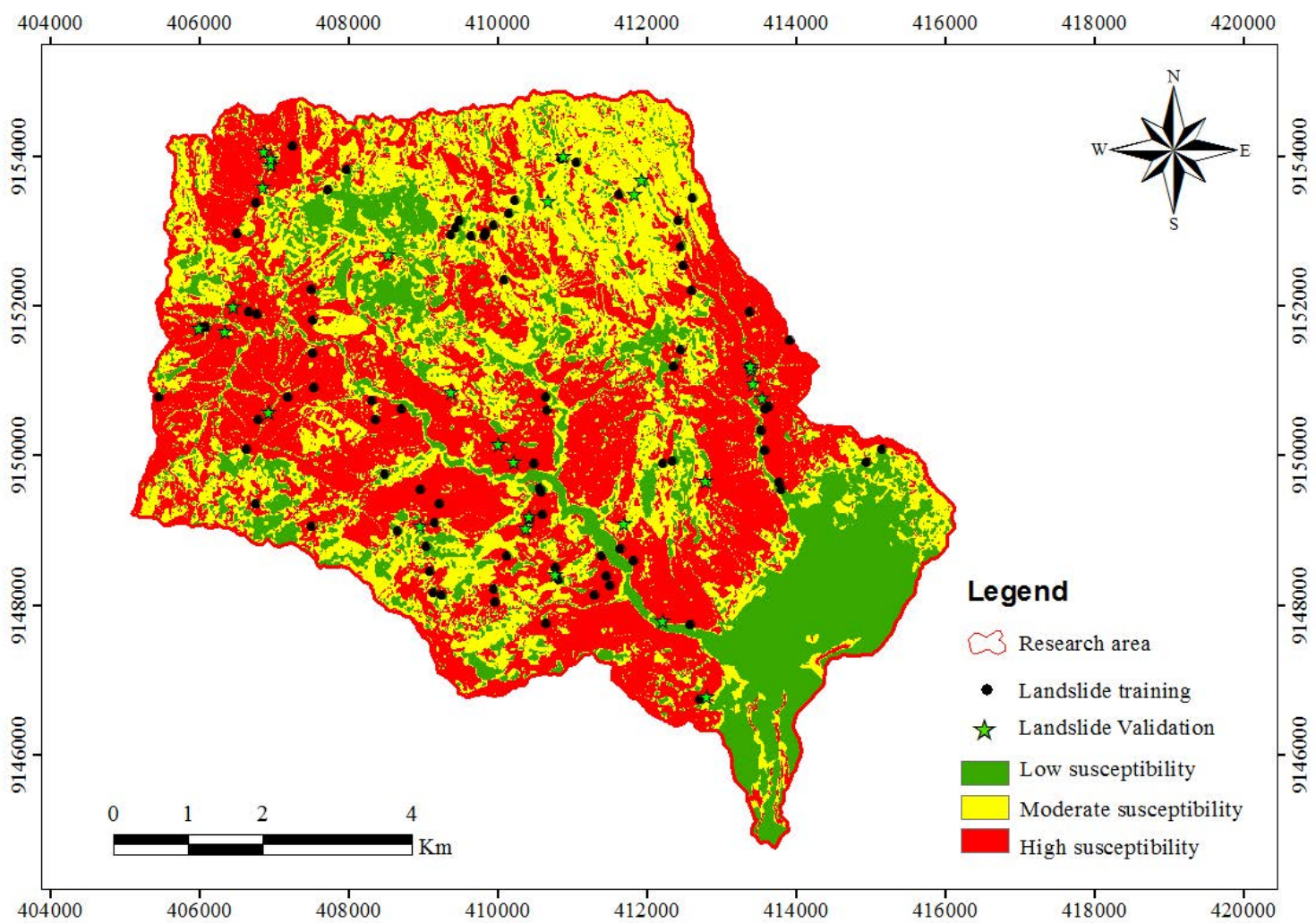

Figure 7: Landslide susceptibility mapdeveloped usingthe LR approach.

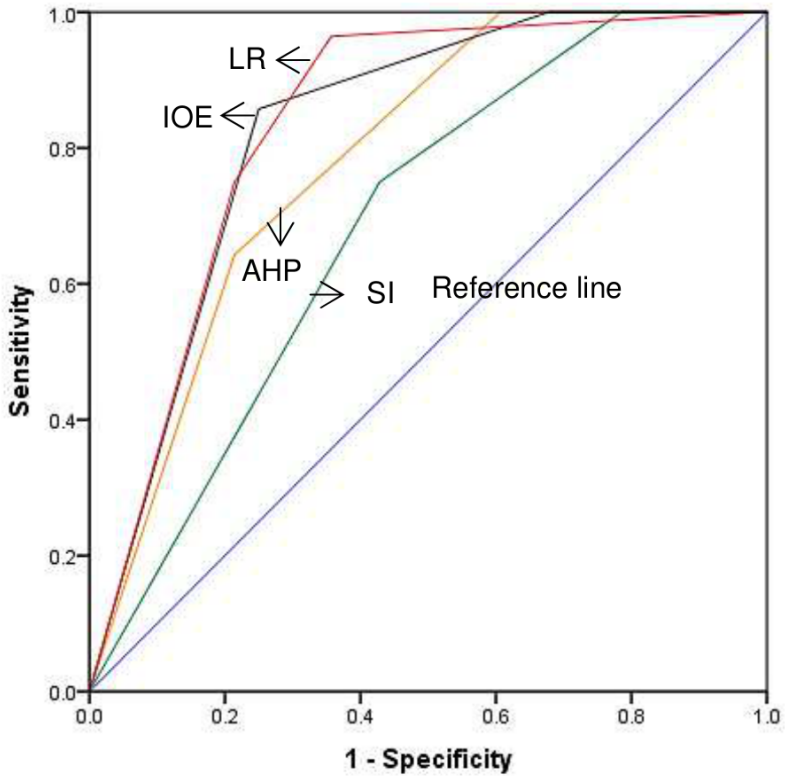

Figure 8: ROC curves of the landslide susceptibility analysis results.
The AHP approach was found to have a good prediction accuracy $(78.4 \%)$, the SI approachwas found to havean average prediction accuracy $(68.8 \%)$, while the IOE and LR were found to have very good prediction accuracies $(82.7 \%$ and $83.4 \%$ ). The LR approach performed the best in predicting landslide susceptibility the study area.

\section{ACKNOWLEDGEMENTS}

The first author would like to thank the Government of the Republic of Indonesia for the scholarship.

\section{REFERENCES}

Akbari, A., Yahaya, F. B., Azamirad, M., Fanod, M. (2014) Landslide susceptibility mapping using logistic regression analysis and GIS, EJGE, 19.

Aleotti, P., Chowdhury, R. (1999) Landslide hazard assessment: summary review and new perspectives, Bull. Eng. Geol. Environ., 58.

Ayalew, L., Yamagishi, H. (2005) The application of GIS based logistic regression for landslide susceptibility mapping, Geomorphology, 65.

Devkota, K. C., Regmi, A. D., Pourghasemi, H. R., Yoshida, K., Pradhan, B., Ryu, I. C., Dhital, M. R. (2013) Landslide susceptibility mapping using certainty factor, index of entropy and logistic re- 
Table 2: Score and weight assigned in the landslide susceptibility analysis using the AHP approach.

\begin{tabular}{|c|c|c|c|}
\hline Parameter & Class & Score & Weight \\
\hline $\begin{array}{l}\text { Slope } \\
\text { inclination } \\
\left({ }^{\circ}\right)\end{array}$ & $\begin{array}{l}0-2 \\
2-4 \\
4-8 \\
8-16 \\
16-35 \\
35-55 \\
>55\end{array}$ & $\begin{array}{l}1 \\
1 \\
1 \\
2 \\
3 \\
4 \\
5\end{array}$ & 0.30 \\
\hline Lithology & $\begin{array}{l}\text { Limestone } \\
\text { Sandstone } \\
\text { Ash, breccia } \\
\text { and tuff } \\
\text { Sand-clay } \\
\text { deposits } \\
\text { Andesitic } \\
\text { breccia }\end{array}$ & $\begin{array}{l}1 \\
2 \\
3 \\
4 \\
5\end{array}$ & 0.19 \\
\hline $\begin{array}{l}\text { Distance to } \\
\text { fault }(\mathrm{m})\end{array}$ & $\begin{array}{l}>1000 \\
500-1000 \\
0-500\end{array}$ & $\begin{array}{l}1 \\
3 \\
5\end{array}$ & 0.07 \\
\hline Land use & $\begin{array}{l}\text { Rice field } \\
\text { Settlement } \\
\text { Plantation }\end{array}$ & $\begin{array}{l}1 \\
3 \\
5\end{array}$ & 0.25 \\
\hline $\begin{array}{l}\text { Distance to } \\
\text { river }(\mathrm{m})\end{array}$ & $\begin{array}{l}>100 \\
50-100 \\
<50\end{array}$ & $\begin{array}{l}1 \\
3 \\
5\end{array}$ & 0.13 \\
\hline $\begin{array}{l}\text { Rainfall } \\
(\mathrm{mm} / \mathrm{yr})\end{array}$ & $<1800$ & 1 & 0.08 \\
\hline
\end{tabular}

gression models in GIS and their comparison at Mugling-Narayanghat road, Nat Hazards, 65.

Glade, T., Crozrier, M. J. (2005). A review of scale dependency in landslide hazard and risk analysis. Landslide Hazard and Risk, Wiley.

Jaafari, A., Najafi, A., Pourghasemi, H. R., Rezaeian, J., Sattarian, A. (2014) GIS-based frequency ratio and index of entropy models for landslide susceptibility assessment in the Caspian forest, northern Iran, Int. J. Environ. Sci. Technol,11, 4.

Kavzoglu, T., Sahin, E. K., Colkesen, I. (2015) An assessment of multivariate and bivariate approaches in landslide susceptibility mapping: a case study of Duzkoy district, Nat Hazards, 76.

Lee, E. M., and Jones, D. K. (2004) Landslide risk assessment, Thomas Telford, London.

Lee, S., Pradhan, B. (2007) Landslide hazard mapping at Selangor, Malaysia using frequency ratio and logistic regression models, Landslides, 4.

Mancini, F., Ceppi, C., Ritrovato, G. (2010) GIS and statistical analysis for landslide susceptibility mapping in the Daunia area, Italy, Nat. Hazards Earth Syst. Sci., 10.

Pourghasemi, H. R., Moradi, H. R., Aghda, S. M. (2013) Landslide susceptibility mapping by binary logistic regression, analytical hierarchy process, and statistical, Nat Hazards 69, 1.

Prabin, K. (2010) Landslide susceptibility mapping and hazard assessment in the Nepal Himalaya.

Pradhan, B. (2010) Manifestation of an advanced fuzzy logic model coupled with Geo-information techniques to landslide susceptibility mapping and their comparison with logistic regression modelling, Environ Eco Stat,18, 3.

Rahardjo, W, Sukandarrumini, and Rosidi, H.M.S. (1995) Geological Map of Yogyakarta Sheet, Java, Geological Research and Development Centre.

Saaty, T. L. (1980) The analytic hierarchy process: planning, priority setting, resource allocation, McGraw-Hill Book Co, New York.

Shahabi, H., Ahmad, B., Kezri, S. (2013) Evaluation and comparison of bivariate and multivariate statistical methods for landslide susceptibility mapping (case study: Zab Basin), Arab J Geosci, 6.

Wang, Q., Li, W., Chen, W., Bai, H. (2015) GIS-based assessment of landslide susceptibility using certainty factor and index of entropy models for the Qianyang County of Baoji city, China, J. Earth Syst. Sci. 124, 7 .

Wang, Q., Li, W., Wu, Y., Pei, Y., Xie, P. (2016) Application of statistical index and index of entropy methods to landslide susceptibility assessment in Gongliu (Xinjiang, China), Environ Earth Sci., 75.

Yalcin, A. (2008) GIS-based landslide susceptibility mapping using analytical hierarchy process and bivariate statistics in Ardesen (Turkey): Comparisons of results and confirmations, Catena, 72.

Yesilnacar, E., Topal, T. (2005) Landslide susceptibility mapping: A comparason of logistic regression and neural networks methods in a medium scale study, Hendek region (Turkey), Engineering Geology, 79, 3-4.

Youssef, A. M., Pradhan, B., Jebur, M. N., El-Harbi, H. M. (2015) Landslide susceptibility mapping using ensemble bivariate and multivariate statistical models in Fayfa area, Saudi Arabia, Environ Earth Sci, 73 .

Van Den Eckhaut, M., Vanwalleghem, T., Poesen, J., Govers, G., Vandekerchove, L. (2006) Prediction of landslide susceptibility using rare events logistic regression: A case study in the Flemish Ardennes, Geomorphology, 76, 3-4.

Van Westen, C. J. (1997) Statistical landslide hazard analysis, ILWIS 2.1 for Windows application guide, ITC Publication, Enschede.

Voogd, H. (1983) Multi criteria evaluation for urban and regional planning, Pion, London. 
Table 3: Weight of each class in landslide susceptibility analysis using the SI approach.

\begin{tabular}{|c|c|c|c|c|}
\hline Parameter & Class & $\begin{array}{l}\text { Pixel number of } \\
\text { class }\left(P_{i j}\right)\end{array}$ & $\begin{array}{c}\text { Number of } \\
\text { landslide }\left(L_{i j}\right)\end{array}$ & Weight $\left(W_{i j}\right)$ \\
\hline \multirow{7}{*}{ Slope inclination $\left(^{\circ}\right)$} & $0-2$ & 261562 & 0 & 0 \\
\hline & $2-4$ & 86142 & 0 & 0 \\
\hline & $4-8$ & 194674 & 1 & -1.88 \\
\hline & $8-16$ & 534485 & 21 & 0.16 \\
\hline & $16-35$ & 1218490 & 58 & 0.35 \\
\hline & $35-55$ & 262662 & 6 & -0.38 \\
\hline & $>55$ & 5249 & 0 & 0 \\
\hline \multirow{5}{*}{ Lithology } & Sand-clay deposit & 162615 & 2 & -1 \\
\hline & Ash, breccia and tuff & 93129 & 0 & 0 \\
\hline & Sandstone & 67860 & 0 & 0 \\
\hline & Limestone & 212134 & 3 & -0.86 \\
\hline & Andesitic breccia & 2027526 & 81 & 0.17 \\
\hline \multirow{3}{*}{ Distance to fault (m) } & $0-500$ & 1183810 & 49 & 0.21 \\
\hline & 500-1000 & 767510 & 18 & -0.36 \\
\hline & $>1000$ & 611944 & 19 & -0.08 \\
\hline \multirow{3}{*}{ Land use } & Rice field & 428234 & 3 & -1.57 \\
\hline & Plantation & 1770826 & 60 & 0.01 \\
\hline & Settlement & 364204 & 23 & 0.63 \\
\hline \multirow{3}{*}{ Distance to river (m) } & $0-50$ & 859137 & 23 & -0.23 \\
\hline & 50-100 & 662865 & 21 & -0.06 \\
\hline & $>100$ & 1041262 & 42 & 0.18 \\
\hline \multirow{3}{*}{ Rainfall (mm/yr) } & $<1800$ & 326728 & 3 & -1.3 \\
\hline & $1800-2000$ & 1018412 & 44 & 0.25 \\
\hline & $>2000$ & 1218124 & 39 & -0.05 \\
\hline
\end{tabular}


Table 4: Weight of each parameter in landslide susceptibility analysis using the IOE approach.

\begin{tabular}{|c|c|c|c|c|c|c|c|c|c|c|}
\hline Parameter & Class & $a$ & $b$ & $P_{i j}$ & $\left(P_{i j}\right)$ & $H_{j}$ & $H_{j_{\max }}$ & $I_{j}$ & $P_{j}$ & $W_{j}$ \\
\hline \multirow{7}{*}{ Slope inclination $\left(^{\circ}\right)$} & $0-2$ & 10.2 & 0 & 0 & 0 & \multirow{7}{*}{1.72} & \multirow{7}{*}{2.81} & \multirow{7}{*}{0.39} & \multirow{7}{*}{0.49} & \multirow{7}{*}{0.19} \\
\hline & $2-4$ & 3.36 & 0 & 0 & 0 & & & & & \\
\hline & $4-8$ & 7.59 & 1.16 & 0.15 & 0.04 & & & & & \\
\hline & $8-16$ & 20.85 & 24.42 & 1.17 & 0.34 & & & & & \\
\hline & $16-35$ & 47.54 & 67.44 & 1.42 & 0.41 & & & & & \\
\hline & $35-55$ & 10.25 & 6.98 & 0.68 & 0.2 & & & & & \\
\hline & $>55$ & 0.2 & 0 & 0 & 0 & & & & & \\
\hline \multirow{5}{*}{ Lithology } & Sand-clay & 6.34 & 84.88 & 0.37 & 0.19 & \multirow{5}{*}{1.37} & \multirow{5}{*}{2.32} & \multirow{5}{*}{0.41} & \multirow{5}{*}{0.4} & \multirow{5}{*}{0.16} \\
\hline & Ash breccia & 3.63 & 2.33 & 0 & 0 & & & & & \\
\hline & Sandstone & 2.65 & 6.98 & 0 & 0 & & & & & \\
\hline & Limestone & 8.28 & 3.49 & 0.42 & 0.21 & & & & & \\
\hline & Andesitic breccia & 79.1 & 94.19 & 1.19 & 0.60 & & & & & \\
\hline \multirow{3}{*}{ Distance to fault (m) } & $0-500$ & 46.18 & 56.98 & 1.23 & 0.43 & \multirow{3}{*}{1.55} & \multirow{3}{*}{1.58} & \multirow{3}{*}{0.02} & \multirow{3}{*}{0.95} & \multirow{3}{*}{0.02} \\
\hline & $500-1000$ & 29.94 & 20.93 & 0.7 & 0.24 & & & & & \\
\hline & $>1000$ & 23.87 & 22.09 & 0.93 & 0.32 & & & & & \\
\hline \multirow{3}{*}{ Land use } & Rice Field & 16.71 & 3.49 & 0.21 & 0.07 & \multirow{3}{*}{1.23} & \multirow{3}{*}{1.58} & \multirow{3}{*}{0.23} & \multirow{3}{*}{1.03} & \multirow{3}{*}{0.23} \\
\hline & Plantation & 69.08 & 69.77 & 1.01 & 0.33 & & & & & \\
\hline & Settlement & 14.21 & 26.74 & 1.88 & 0.61 & & & & & \\
\hline \multirow{3}{*}{ Distance to river $(\mathrm{m})$} & $0-50$ & 33.52 & 26.74 & 0.8 & 0.27 & \multirow{3}{*}{1.56} & \multirow{3}{*}{1.58} & \multirow{3}{*}{0.01} & \multirow{3}{*}{0.98} & \multirow{3}{*}{0.01} \\
\hline & $50-100$ & 25.86 & 24.42 & 0.94 & 0.32 & & & & & \\
\hline & $>100$ & 40.62 & 48.84 & 1.2 & 0.41 & & & & & \\
\hline \multirow{3}{*}{ Rainfall (mm/yr) } & $<1800$ & 12.75 & 3.49 & 0.27 & 0.11 & & & & & \\
\hline & $1800-2000$ & 39.73 & 51.16 & 1.29 & 0.51 & 1.37 & 1.58 & 0.13 & 0.84 & 0.11 \\
\hline & $>2000$ & 47.52 & 45.35 & 0.95 & 0.38 & & & & & \\
\hline
\end{tabular}

Table 5: Logistic regression coefficient of each parameter in the landslide susceptibility analysis using the LR approach.

\begin{tabular}{lc}
\hline Parameter & Logistic regression coefficient \\
\hline Slope inclination $\left(\beta_{1}\right)$ & 1.02 \\
Lithology $\left(\beta_{2}\right)$ & 0.365 \\
Distance to fault $\left(\beta_{3}\right)$ & -0.503 \\
Land use $\left(\beta_{4}\right)$ & 0.916 \\
Distance to river $\left(\beta_{5}\right)$ & 0.308 \\
Rainfall intensity $\left(\beta_{6}\right)$ & -0.553 \\
Constant $\left(\beta_{0}\right)$ & -5.86 \\
\hline
\end{tabular}


Table 6: Density of landslides in each landslide susceptibility zone.

\begin{tabular}{lccc}
\hline Susceptibility level & Area of susceptibility zone $(\%)$ & Areaof landslide $(\%)$ & Densityof landslide \\
\hline AHP & & & \\
Low & 15.08 & 1.16 & 0.08 \\
Moderate & 29.91 & 38.37 & 1.28 \\
High & 55.01 & 60.49 & 1.1 \\
\hline SI & & & \\
Low & 11.03 & 1.16 & 0.11 \\
Moderate & 40.81 & 23.26 & 0.57 \\
High & 48.15 & 75.58 & 1.57 \\
\hline IOE & & & \\
Low & 8.84 & 2.93 & 0.27 \\
Moderate & 26.33 & 9.3 & 0.35 \\
High & 65.19 & 88.37 & 1.36 \\
\hline LR & & & \\
Low & 22.62 & 3.49 & 0.15 \\
Moderate & 31.85 & 31.4 & 0.99 \\
High & 45.53 & 65.12 & 1.43 \\
\hline
\end{tabular}

